Mewhort-Buist, T. A., \& Nilsen, E. S. (2017) Shy individuals' interpretation of counterfactual verbal irony. Metaphor \& Symbol, 32, 262-275. https://doi.org/10.1080/10926488.2017.1384275

This is an Accepted Manuscript of an article published by Taylor \& Francis in Metaphor and Symbol on 2017-10-31, available online: http://www.tandfonline.com/https:// doi.org/10.1080/10926488.2017.1384275.

\title{
Shy Individuals' Interpretations of Counterfactual Verbal Irony
}

Tracy A. Mewhort-Buist ${ }^{\mathrm{a}} \&$ Elizabeth S. Nilsen ${ }^{\mathrm{a}}$

${ }^{a}$ Centre for Mental Health Research, Department of Psychology, University of Waterloo, 200 University Avenue West, Waterloo, Ontario, Canada, N2L 3G1

Correspondence concerning this article should be addressed to: Elizabeth Nilsen, Department of Psychology, University of Waterloo, 200 University Avenue West, Waterloo, Ontario, Canada, N2L 3G1. Email: enilsen@uwaterloo.ca; Phone: 519-888-4567 ext. 33991. 


\begin{abstract}
Counterfactual verbal irony, an evaluative form of figurative language wherein a speaker's intended meaning is opposite to the literal meaning of his or her words, is used to serve many social goals. Despite recent calls for theoretical accounts to include the factors that influence irony interpretation (Gibbs \& Colston, 2012), few studies have examined the individual differences that may impact verbal irony interpretation. The present study examined whether adults with elevated shyness would generate more negative interpretations of ironic statements. University students with varying degrees of shyness listened to stories (accompanied by comics) wherein one character made literal or ironic criticisms or compliments to another character. Participants then appraised each speaker's belief and attitude. Self-reported shyness did not predict comprehension of the counterfactual nature of ironic statements. However, shyer adults rated speakers who made ironic compliments as being meaner than did adults low in shyness. Thus, while understanding that ironic speakers intended to communicate their true beliefs, shyer individuals construed the social meaning of irony more negatively. Such interpretive biases may lead shy individuals to more frequently take offence at ironic compliments and experience more negativity in social interactions.
\end{abstract}

Keywords: shyness, verbal irony, pragmatics, figurative language, social anxiety, sarcasm 


\section{Shy Individuals' Interpretations of Counterfactual Verbal Irony}

Effective communication requires more than just understanding the structure (syntax) and meaning (semantics) of language. Much of what we say is ambiguous; the intended meaning of our statements cannot always be gleaned by the literal meanings of the words alone. Figurative statements highlight this ambiguity by using words whose literal meanings differ in critical ways from the speaker's intended meaning. Counterfactual verbal irony (often referred to as sarcasm) is one form of figurative language, in which the intended meaning is directly opposite to the literal meaning of the spoken words (Katz \& Lee, 1993). Verbal irony in which the intended meaning is negative or mocking can be used to criticize a situation or a person, such as saying, "Boy, that was an awesome shot!", after someone misses a critical shot in golf. Irony in which the intended meaning is positive can be used to compliment others, such as saying, "You are such an awful gardener", after a friend shows you her amazing garden. Counterfactual verbal irony carries with it a degree of social ambiguity since it includes elements of both humour and aggression (Shapiro, Baumeister, \& Kessler, 1991). Given the inherent ambiguity of verbal irony, it is not surprising that interpretations are not necessarily the same for each person. Rather, individuals can draw a range of meanings depending on a variety of interacting factors (age, language experience, culture, etc., Gibbs \& Colston, 2012). To understand the dynamic complexities involved in interpreting figurative language, it is important to have a clear idea of which individual factors play a role. Addressing this need, the present work focused on the role of temperamental characteristics, in particular a shy or anxious temperament, for the interpretation of counterfactual irony.

As noted above, counterfactual irony carries with it the potential for gross misinterpretation, because the intended meaning is qualitatively different from the literal meaning, which could lead to negative social consequences. As such, some people could 
question why anyone would use ironic language at all. Yet, irony is used in $8 \%$ of conversations (Gibbs, 2000), and young adults use figurative language in almost all emails (i.e., 94\%), although verbal irony is used less frequently than hyperbole (Whalen, Pexman, \& Gill, 2009). People use verbal irony to serve a number of important social functions. For example, as noted above, irony can convey both humorous and aggressive intentions. This is particularly apparent for ironic compliments, which may be used when a speaker is envious of a listener's accomplishments (Dews, Kaplan, \& Winner, 1995; Pexman \& Zvaigzne, 2004), or to highlight a listener's selfdeprecating statements or unwarranted expectations of failure (Garmendia, 2010). Research has also shown that individuals use verbal irony to be jocular, to mock, to distance themselves emotionally, and to soften insults (Dews et al, 1995; Gibbs \& Izett, 1999, Pexman \& Zvaigzne, 2004). The Tinge Hypothesis suggests that speakers can achieve the positive social goals of softening insults, saving face, and preserving relationships by using irony to convey criticism because the critical meaning of the statement is muted by the literal word meaning (Dews \& Winner, 1995). Thus, since ironic criticisms are considered less negative than literal criticisms, speakers may state their opinions in a less aggressive manner. However, according to the same principle, compliments are rendered less positive when irony is used, due to the same mechanism. Both children and adults' ratings show appreciation of the muting function of verbal irony: ironic criticisms are rated as less mean than literal criticisms, and ironic compliments as less nice than literal compliments starting at the age of 5-6 years (e.g., Dews \& Winner, 1995; Harris \& Pexman, 2003; Mewhort-Buist \& Nilsen, 2012; Pexman \& Glenwright, 2007).

In order for verbal irony to serve these social functions, both speakers and listeners must have sufficient communicative and social competence in order to fully appreciate the implied meaning of the utterance. Research in children has demonstrated that understanding verbal irony 
is related to a number of basic social-cognitive skills including perspective-taking (or "theory of mind") and vocabulary (Filippova \& Astington, 2008; Nilsen, Glenwright, \& Huyder, 2011). While there is some understanding of the socio-cognitive skills that contribute to irony understanding, there is a paucity of research examining how individual differences in temperament or personality play a role. Personality style has been found to influence the production of ironic language. For example, people who view themselves as agreeable were less likely to use sarcasm to diffuse embarrassing situations (Markowitz, 2007 as cited in Gibbs \& Colston, 2012) and certainly others view sarcastic speakers as possessing certain characteristics (e.g., humorous, insincere, and less educated; Pexman \& Olineck, 2002). However, it is not known the extent to which personality features impact one's comprehension or interpretation of ironic language.

One temperamental style that may be relevant for ironic language interpretation, due to its association with socio-communicative competence generally, is shyness. Shyness develops from a young age, particularly for individuals who demonstrated a 'behaviorally inhibited' temperamental style as children, meaning they possessed a biologically-based tendency to withdraw in unfamiliar situations (Kagan, 1989). Children with this temperament are characterized as quiet, vigilant and restrained when they are in novel situations. Shy individuals are often thought to experience a conflict in approach and avoidance motivations, such that they simultaneously desire to approach their peers, and are equally motivated to avoid others due to anxiety (Asendorpf, 1990). Although shyness is considered a temperamental or personality trait on a continuum of typical behaviour, individuals with extreme shyness may experience distress in social situations, at which point they would be characterized as having social anxiety. 
Shy adults show differences in how they detect and integrate social information, such as tone of voice and the overall social context. For example, shyness was found to be negatively correlated to performance on the Interpersonal Perception Task, where participants were asked to interpret non-verbal social cues from a video (Schroeder, 1995). In addition, research has demonstrated that individuals with social anxiety tend to interpret ambiguous social scenarios in negative ways, and to catastrophize mildly negative social situations (Stopa \& Clark, 2000). There is also research to suggest that while non-anxious individuals tend to have a positivity bias in social situations (i.e. tending to interpret neutral or ambiguous social stimuli in a positive light), this is absent for those with social anxiety (Constans, Penn, Ihen, \& Hope, 1999). However, it is not clear whether the interpretation of verbal irony, which relies on successful integration of a number of cues (tone of voice, discrepancy between context and literal statement; Ackerman, 1983; Capelli, Nakagawa, \& Madden, 1990; Glenwright, Parackel, Cheung, \& Nilsen, 2014; Keenan \& Quigley, 1999; Pexman, Whalen, \& Green, 2010) could be challenging for shy individuals.

Previous research has demonstrated that shy children attribute a more negative attitude to speakers using verbal irony than do less shy children (Mewhort-Buist \& Nilsen, 2013). However, such findings could reflect the influence of shyness at a particular developmental stage, that is, one in which irony comprehension is emergent. Adults, being more experienced in the comprehension and use of verbal irony, may not experience the level of ambiguity required to trigger the social biases commonly associated with shyness and social anxiety. Furthermore, developmental research has shown that interpretation of ambiguous language does not always follow a linear trajectory. For example, when processing speech which shows discrepant linguistic versus prosodic emotion cues infants (up to 18 months of age) attend more to prosodic 
cues, whereas children aged 4-10 years rely primarily on the linguistic content of the utterance to interpret the emotion, and finally, adults return to attending more to the prosody (Friend, 2001; Friend \& Bryant, 2000; Morton \& Trehub, 2001). The present study sought to provide insight into the impact of individual differences in temperamental style on verbal irony within a population that has accrued years of experience with this language form.

\section{Method}

\section{Participants}

Participants completed the Revised Cheek and Buss 20-Item Shyness Scale (Cheek \& Melichor, 1985) as part of a mass testing session used within a university subject pool so that individuals high in shyness could be over-represented in the sample. The initial sample consisted of 110 students. Eleven participants were excluded due to incomplete data. Those participants who did not learn English as their first language were excluded $(n=36)$ since it has been shown that there are differences in figurative language understanding in individuals' second language, even when they are fully proficient in the second language (Bromberek-Dyzman \& Ewert, 2010). In addition, preliminary analyses revealed that the results yielded from one version of the task differed from those yielded from the other three versions (counterbalancing yielded four versions of the task, as described below). Closer analysis of this version revealed less certainty in the ratings of speaker's tone-of-voice on ironic compliments for this version of the task (see below for more information on tone-of-voice ratings) compared to the other versions $(F(3,11)=5.21, p$ $=.028)$. As a result, those participants completing this version of the task were excluded ( $n=$ 17). The final sample, therefore, included 46 participants $\left(M_{a g e}=20.4\right.$ years, $30 \%$ male).

\section{Materials and Procedure}


Verbal Irony Task. The verbal irony task was comprised of 12 stories depicting a female and a male character engaging in various activities, such as soccer and mini-golf. The story events took place in either a negative or a positive context (e.g. a character completely missing the goal, or a character scoring a goal playing soccer, respectively), followed by a statement (literal or ironic) made by the other character in the story (see Appendix A for an example with its comic, see Appendix B for a list of all the stories used in the study). The statement was either a criticism or a compliment depending on the context of the story. That is, 4 versions of each story were created (i.e., 48 stories), in which each speaker made a literal or ironic criticism (negative context) or a literal or ironic compliment (positive context). Stories were of equal length in terms of number of words and number of sentences. Gender of speaker was counterbalanced across participants for each story type. Each participant heard one version of each of the 12 stories, and the 4 versions of each story were counterbalanced across participants, so that all 48 stories were approximately equally represented. There were thus four sets of 12 stories; although, as noted above, one set was excluded from analyses.

The stories were presented by computer, with each story narrated by the same female speaker, accompanied by comic strips to aid in interest and memory for the story. The final statements made by the speakers were presented with appropriate intonation, since it has been shown that irony is more easily understood when spoken with appropriate tone-of-voice (Keenan \& Quigley, 1999; Woodland \& Voyer, 2011). That is, the literal criticisms were made using a blunt, sincere tone; the ironic criticisms were made using a mocking tone; the literal compliments were made using a pleasant, sincere tone; and the ironic compliments were made using a pleasant, teasing tone. To assess the tone of the statements, the final statements from each story were isolated from the rest of the recording and presented without the comics to 
psychology graduate students who rated each statement as "literal" or "ironic". Any statement that was not endorsed as being the appropriate statement type was re-recorded until greater than $50 \%$ of raters agreed that the intonation matched the statement type (a minimum of 10 graduate students rated each story). A $t$-test comparing the literal and ironic intonation ratings of the final recordings confirmed that the ratings significantly differed $(t(34)=15.75, p<.001)$. Raters correctly identified literal or ironic statements based on speaker tone of voice for $84 \%$ and $97 \%$ of literal criticisms and compliments, respectively, and for $88 \%$ and $77 \%$ of ironic criticisms and compliments, respectively.

Participants completed the 12 experimental stories in a fixed order with the 4 story types presented in a pseudo-randomized order. Following each story, participants were asked questions to assess their understanding of 1) speaker belief and, 2) speaker intention. In the speaker belief question participants indicated whether the speaker thought the object of the final statement was "good" or "bad". When responding to the speaker intention question participants used a 9-point Likert scale ranging from (4) "extremely nice" to (-4) "extremely mean" to rate the speaker's attitude.

Receptive Vocabulary Measure. Participants were assessed on their receptive vocabulary using the Peabody Picture Vocabulary Task, Third Edition (PPVT-III; Dunn \& Dunn, 1997), since shyness has been associated with language difficulties (e.g. Evans, 1996). On this task, participants were asked to point to pictures representing the spoken words of the researcher, according to the standardized instructions. The total raw score was used for subsequent analyses.

Shyness and Depression Measures. At the time of testing, participants again completed the Revised Cheek \& Buss 20-Item Shyness Scale, a self-report measure consisting of 20 items assessing adult experiences of shyness (Cheek \& Melichor, 1985). According to the developer's 
website, this measure has an internal consistency reliability of .94 (Cheek, n.d.), and it has been shown to have a 45 day test-retest reliability of .91 , and to correlate (.69) with shyness ratings from family members and close friends (Melchior \& Cheek, 1990). Self-report measures, including the three versions of this measure, are widely used in the contemporary study of adult shyness (e.g., Jetha, Zheng, Goldberg, Segalowitze, \& Schmidt, 2013; Fallah, 2014; Rowsell \& Coplan, 2013) and it has been shown to have sound psychometric properties (Crozier, 2005). The Beck Depression Inventory, second edition (BDI-II, Beck, Steer, \& Brown, 1996) was used as a potential covariate since shyness has been associated with depressive symptoms (e.g. Traub, 1983), and depression has also been related to the interpretation of social cues (i.e., emotional facial expressions; Harkness, Sabbagh, Jacobson, Chowdrey, \& Chen, 2005; Lee, Harkness, Sabbagh, \& Jacobson, 2005). Raw scores from self-report measures were used for analyses.

\section{Results}

To examine the overall results, univariate repeated measures ANOVAs with story type as the within-subject variable were used to explore the speaker belief and speaker intention questions. Since the ANOVAs violated the assumption of sphericity $(W(5)=.33-.76, p s<.05)$, the Greenhouse-Geisser correction was applied. For the speaker belief question, the ANOVA revealed a main effect of story type $\left(F(1.75,78.58)=3.59, \eta_{\mathrm{p}}{ }^{2}=.07, p=.04\right.$; Figure 1$)$. Planned follow-up analyses revealed that participants made more errors on ironic compliments when compared to literal compliments $(t(45)=2.20, p=.03)$, ironic criticisms $(t(45)=2.46, p=.02)$ and literal criticisms (although the latter finding was marginally significant; $t(45)=1.77, p=$ .08). As can be seen in Figure 1, while participants were near ceiling in their responses to the speaker belief question for literal or ironic criticisms, and literal compliments, they responded as though ironic compliments were literal criticisms (i.e., that the speaker believed the performance 
of the addressee was "bad") on approximately $6 \%$ of the trials. For examination of the speaker intent question, only those trials where the participant was accurate on the speaker belief question were included, because understanding that the speaker's belief differs from the literal meaning of the statement is necessary for understanding irony. As shown in Figure 2, a main effect of story type was found $\left(F(2.56,115.27)=297.33, \eta_{\mathrm{p}}{ }^{2}=.88, p<.001\right)$. Follow-up t-tests revealed that while there was not a significant difference in attitude ratings between literal and ironic criticisms $(t(45)=1.67, p=.10)$, speakers who made ironic compliments were rated as being significantly less nice than those who made literal compliments $(t(45)=8.00, p<.001)$.

Bivariate correlations were used to examine the relationships between shyness and interpretations of ironic language (Table 2). As there was no significant relationship found between shyness and receptive vocabulary (PPVT-III, $r(44)=.10, p=.19$ ) or between shyness and symptoms of depression (BDI-II, $r(44)=.25, p=.10$ ); these variables were not used as covariates in subsequent analyses. For the speaker belief questions, shyness was not significantly related to participants' understanding of the counterfactual nature of verbal irony for either ironic criticisms or ironic compliments, suggesting that shyness does not influence the ability to appreciate that ironic speakers mean the opposite of the literal meaning of their words. In contrast, for the speaker intent questions, while shyness was not significantly related to ratings of speakers' attitudes on ironic criticisms $(r(44)=-.01, p=.95)$, it was significantly related to ratings of speakers' attitudes on ironic compliments $(r(44)=-.44, p<.01)$. The higher a participant's self-reported levels of the shyness, the lower he or she rated the speaker on “niceness" for ironic compliments. Participants' ratings of speaker "niceness" for the other story types were not significant $(p s \geq .09)$ suggesting that shyness was not associated with a general negativity bias. 


\section{Discussion}

While verbal irony has a rich history of examination, the present study filled a noted void in examining the degree to which individual differences impact interpretation. Filling this gap, the present work examined the impact of shy temperament on individuals' interpretation of counterfactual irony. Across all individuals, ironic compliments were rated as being meaner than literal compliments, consistent with the muting function of irony as proposed by Tinge Hypothesis. Importantly, the muting of ironic compliments was affected by the participants' level of shyness: individuals with higher levels of shyness, despite showing an ability to recognize the counterfactual nature of ironic compliments, rated the speaker's attitude to be meaner. When using an ironic compliment, the speaker conveys praise by saying something negative (i.e. opposite to the context). Therefore, since shyness was related to more negative perceptions of speakers who use ironic compliments, very shy individuals may be unlikely to experience ironic compliments as forms of praise.

Research into the ways in which individuals with social anxiety process sociocommunicative information provides insight into the mechanisms that may account for these findings. For example, findings are consistent with research showing that socially anxious individuals interpret ambiguous or mildly negative social interactions in overly negative ways (Stopa \& Clark, 2000). It may be the case that the conflicting elements of praise and teasing inherent in ironic compliments creates enough ambiguity to trigger shy individuals' biases towards threat. Relatedly, individuals with social anxiety tend to show increased attention biases towards threatening words (see Rapee \& Heimberg, 1997 for a review) and towards angry faces, compared to neutral or happy faces (Mogg, Philippot, \& Bradley, 2004). At the same time, socially anxious individuals direct their attention away from faces to a greater extent than neutral 
stimuli (Chen, Ehlers, Clark \& Mansell, 2002). As such, when faced with information that is both positively and negatively valenced (as with ironic compliments), they may attend more to the negative information (the words) and attend less to the positive information (social cues to indicate the words are not meant to be taken literally). Moreover, Hezel and McNally (2014) found that individuals with social anxiety disorder tended to attribute more intense emotions and greater meaning to the thoughts and feelings of others than did individuals without social anxiety disorder. Within the communicative domain, this may mean that shy individuals over-interpret the intentions of ironic speakers thereby attributing more negative or hostile intentions, as demonstrated in the present study.

Together with our previous research (Mewhort-Buist \& Nilsen, 2013), the current study demonstrates that across the lifespan, shyer individuals perceive ironic speakers as being more negative than do individuals who are lower in shyness. However, interestingly, while for children, the negative interpretation of ironic speakers was found primarily when they made ironic criticisms (although there was a marginal effect for ironic compliments; Mewhort-Buist \& Nilsen, 2013), in the current study, this result was found only for ironic compliments. It may be the case that by adulthood, individuals have enough experience with ironic criticisms (a more common form of counterfactual verbal irony, Dews \& Winner, 1997), such that there is less room for individual temperaments to play a role. Indeed, we found that the participants in this study comprehended ironic criticisms as well as they did literal remarks, suggesting the ambiguity was easily resolved in ironic criticisms for this sample. In contrast, within a child populations, where the ability to interpret this type of language form is more emergent, shy children viewed the ironic criticisms as more mean than did less shy children. In the adult population, we find that ironic compliments continue to pose interpretive challenges in general 
(as per the accuracy rates) and it is within these comments where participants' temperamental style played a role. As such, it appears that in ironic utterances that pose more confusion for individuals (i.e., ironic criticisms for children, ironic compliments for adults) a shy temperament leads to interpretations of speakers' intentions as being harsher.

The relation between shyness and interpretation of the attitude of ironic speakers does not appear to be a result of impaired basic language skills, since shyness was not related to receptive vocabulary in this sample. Furthermore, no significant association between shyness and depression symptoms was found, making it unlikely that the results are due to mood differences in the shyer individuals. This latter finding was somewhat surprising since research in adults has typically found a relationship between self-reported shyness and self-reported depression in undergraduate samples (e.g., Bell, Jasnoski, Kagan, \& King, 1990; Schmidt \& Fox, 1995); although, this finding is not universal (Bruch \& Belkin, 2001). It is worth noting that the correlation found between shyness and the BDI-II, although not statistically significant, was in the predicted direction, suggesting that the relationship between shyness and depression may not have been found due to a lack of power. It is also unlikely that the observed difference in attitude ratings for ironic speakers was due to a general negativity bias for shyer individuals, since shyness was not related to speaker ratings for literal statements, or for ironic criticisms. Instead, consistent with the previously stated research showing that individuals who are anxious in social situations tend to interpret ambiguous stimuli as threatening, it is likely that the increased inference required for resolving the ambiguity inherent in ironic compliments allows for threat sensitivities to be revealed.

The present work does not examine the implications for holding more negative interpretations of ironic statements. It may be that such interpretations lead shy individuals to 
take offence more easily in social interactions, thereby leading to adverse social outcomes. That is, it may be that behavioural responses that respond more into the aggressive elements of an ironic compliment (while ignoring the humour element) decrease the social affiliation that can be gained through using ironic language. However, it should also be noted that differences are found for shy individuals even in contexts where the participants were not on the receiving end of the statements. Therefore, interpretive differences do not appear to be about shy individuals' reflection on what the statements mean about them personally; but rather, are more broadlyreaching, influencing their views of third-party interchanges.

It is argued that instead of trying to uncover the one "normative" account of figurative language interpretation, researchers should seek to develop comprehensive accounts that accommodate the varied ways in which individuals may interpret the same ironic statement (Gibbs \& Colston, 2012). This study provides one piece to the complex puzzle through an examination of the role of shy temperament on counterfactual irony interpretation. Shy individuals rated the attitudes of speakers as being meaner than individuals with low degrees of shyness. In addition to providing information about the characteristics that may influence irony interpretation, findings contribute to a growing literature demonstrating biases in aspects of socio-communicative skills for shy individuals. 


\section{References}

Ackerman, B. P. (1983). Form and function in children's understanding of ironic utterances. Journal of Experimental Child Psychology, 35, 487-508.

Asendorpf, J. B. (1990). Beyond social withdrawal: Shyness, unsociability and peer avoidance. Human Development, 33, 250-259.

Beck, A. T., Steer, R. A., \& Brown, G. K. (1996). Beck Depression Inventory, $2^{\text {nd }}$ Ed. San Antonio, Texas, USA: Psychological Corporation.

Bell, I.R., Jasnoski, M.L, Kagan, J., \& King, D.S. (1990). Is allergic rhinitis more frequent in young adults with extreme shyness? A preliminary survey. Psychosomatic Medicine, 52, $517-525$.

Bromberek-Dyzman, K., \& Ewert, A. (2010). Figurative competence is better developed in L1 than in L2, or is it? Understanding conversational implicatures in L1 and L2. In Pütz, M. \& L. Sicola (eds.), Cognitive Processing in Second Language Acquisition: Inside the learner's mind. (pp. 317-334). Philadelphia: John Benjamins Publishing Company.

Bruch, M.A., \& Belkin, D.A. (2001). Attributional style in shyness and depression: Shared and specific maladaptive patterns. Cognitive Therapy and Research, 25, 247-259.

Capelli, C. A., Nakagawa, N., \& Madden, C. M. (1990). How children understand sarcasm: the role of context and intonation. Child Development, 61, 1824-1841.

Cheek, J.M. (n.d.). Shyness Research: The Revised Cheek and Buss Shyness Scale, 20 Item Shyness Scale. Retrieved from http://academics.wellesley.edu/Psychology/Cheek/research.html\#20item.

Cheek, J.M., \& Melichor, L.A. (1985). Measuring the Three Components of Shyness. In M.H. Davis \& S.L. Franzoi (Co-chairs), Emotion, Personality, and Personal Well-Being II. 
Symposium conducted at the annual convention of the American Psychological Association, Los Angeles.

Chen, Y. P., Ehlers, A., Clark, D. M., \& Mansell, W. (2002). Patients with generalized social phobia direct their attention away from faces. Behaviour Research and Therapy, 40, 677687.

Colston, H. L., \& O’Brien, J. (2000). Contrast of kind versus contrast of magnitude: The pragmatic accomplishments of irony and hyperbole. Discourse Processes, 30, 179-199.

Constans, J. I., Penn, D. L., Ihen, G. H., Hope, D. A. (1999). Interpretive biases for ambiguous stimuli in social anxiety. Behaviour Research and Therapy, 37, 643-651.

Crozier, W. R. (2005). Measuring shyness: analysis of the Revised Cheek and Buss Shyness Scale. Personality and Individual Differences, 38, 1947 - 1956.

Dews, S., Kaplan, J., \& Winner, E. (1995). Why not say it directly? The social functions of irony. Discourse Processes, 19, 347-367.

Dews, S., \& Winner, E. (1995). Muting the meaning: A social function of irony. Metaphor and Symbolic Activity, 10, 3-19.

Dews, S., \& Winner, E. (1997). Attributing meaning to deliberately false utterances: The case of irony. In C. Mandell and A. McCabe (Eds.), The problem of meaning: Behavioral and cognitive perspectives. (pp. 377-414). Amsterdam, Netherlands: Elsevier Science.

Dunn, L. M., \& Dunn, L. M. (1997). Peabody Picture Vocabulary Test, $3^{\text {rd }}$ Ed. Circle Pines, Minnesota, USA: American Guidance Service.

Evans, M. A. (1996). Reticent primary grade children and their more talkative peers: Verbal, nonverbal, and self-concept characteristics. Journal of Educational Psychology, 88, 739749. 
Fallah, N. (2014). Willingness to communicate in English, communication self-confidence, motivation, shyness and teacher immediacy among Iranian English-major undergraduates: A structural equation modeling approach. Learning and Individual Differences, 30, 140-147.

Filippova, E., \& Astington, J. W. (2008). Further development in social reasoning revealed in discourse irony understanding. Child Development, 79, 126-138.

Friend, M. (2000). Developmental changes in sensitivity to vocal paralanguage. Developmental Science, 3, 148-162.

Friend, M., \& Bryant, J. B. (2000). A developmental lexical bias in the interpretation of discrepant messages. Merrill-Palmer Quarterly, 46, 342-369.

Garmendia, J. (2010). Irony is critical. Pragmatics \& Cognition, 18, 397-421.

Gibbs, R. W. Jr. (2000). Irony in talk among friends. Metaphor and Symbolic Activity, 15, 5-27.

Gibbs, R. W. Jr., \& Izett, C. D. (1999). Irony as Persuasive Communication (Ch. 6). In L. Colston, \& A. N. Katz, (Eds). Figurative Language Comprehension: Social and Cultural Influences (pp. 131-152). Mahwah, NJ: Lawrence Erlbaum.

Glenwright, M., Parackel, J. M., Cheung, K. R. J., \& Nilsen, E. S. (2014). Intonation influences how children and adults interpret sarcasm. Journal of Child Language, 41, 472-484.

Harkness, K. L., Sabbagh, M. A., Jacobson, J., Chowdrey, N., \& Chen, T. (2005). Enhanced accuracy of mental state decoding in dysphoric college students. Cognition and Emotion, 19, 999-1026.

Harris, M., \& Pexman, P. M. (2003). Children's perceptions of the social functions of verbal irony. Discourse Processes, 36, 147-165. 
Hezel, D. M., \& McNally, R. J. (2014). Theory of mind impairments in social anxiety disorder. Behavior Therapy, 45, 530-540.

Jetha, M. K., Zheng, X., Goldberg, J. O., Segalowitz, S. J., \& Schmidt, L. A. (2013). Shyness and emotional face processing in schizophrenia: An ERP study. Biological Psychology, 94, 562-574.

Kagan, J. (1989). Temperamental contributions to social behavior. American Psychologist, 44, 668-674.

Katz, A. N. \& Lee, C. J. (1993). The role of authorial intent in determining verbal irony and metaphor. Metaphor \& Symbolic Activity, 8, 257-279.

Keenan, T. R. \& Quigley, K. (1999). Do young children use echoic information in their comprehension of sarcastic speech? A test of echoic mention theory. British Journal of Developmental Psychology, 17, 83-96.

Lee, L., Harkness, K. L., Sabbagh, M. A., \& Jacobson, J. A. (2005). Mental state decoding abilities in clinical depression. Journal of Affective Disorders, 86, 247-258.

Melchior, L.A., \& Cheek, J.M. (1990). Shyness and anxious self-preoccupation during a social interaction. Journal of Social Behavior and Personality, 5, 117-130.

Mewhort-Buist, T. A., \& Nilsen, E. S. (2013). What are you really saying? Associations between shyness and verbal irony comprehension. Infant and Child Development, 22, 180-197.

Mogg, K., Philipott, P., \& Bradley, B.P. (2004). Selective Attention to Angry Faces in Clinical Social Phobia. Journal of Abnormal Psychology, 113, 160-165.

Morton, J. B., \& Trehub, S. E. (2001). Children's understanding of emotion in speech. Child Development, 72, 834-843. 
Nilsen, E.S., Glenwright, M., \& Huyder, V. (2011). Children and adults understand that verbal irony interpretation depends on listener knowledge. Journal of Cognition and Development, 12, 374-409.

Pexman, P. M. \& Glenwright, M. (2007). How do typically developing children grasp the meaning of verbal irony? Journal of Neurolinguistics, 20, 178-196.

Pexman, P. M., \& Olineck, K. M. (2002). Understanding Irony: How do stereotypes cue speaker intent? Journal of Language and Social Psychology, 21, 245 - 274.

Pexman, P. M., Whalen, J. M., and Green, J. J. (2010). Understanding verbal irony: Clues from interpretation of direct and indirect ironic remarks. Discourse Processes, 47, 237-261.

Pexman, P. M., \& Zvaigzne, M. T. (2004). Does irony go better with friends? Metaphor and Symbol, 19, 143-163.

Rapee, R. M., \& Heimberg, R. G. (1997). A cognitive-behavioral model of anxiety in social phobia. Behaviour Research and Therapy, 35, 741-756.

Rowsell, H. C., \& Coplan, R. J. (2013). Exploring links between shyness, romantic relationship quality, and well-being. Canadian Journal of Behavioural Sceince, 45, 287-295.

Schmidt, L.A., \& Fox, N.A. (1995). Individual differences in young adults' shyness and sociability: Personality and health correlates. Personality and Individual Differences, 19, $455-462$.

Schroeder, J.E. (1995). Self-concept, social anxiety, and interpersonal perception skills. Personality and Individual Differences, 19, 955-958.

Shapiro, J. P., Baumeister, R. F., \& Kessler, J. W. (1991). A three-component model of children's teasing: aggression, humor, and ambiguity. Journal of Social and Clinical Psychology, $10,459-472$. 
Stopa, L., \& Clark, D. M. (2000). Social Phobia and interpretation of social events. Behaviour Research and Therapy, 38, 273-283.

Traub, G. S. (1983). Correlations of shyness with depression, anxiety, and academic performance. Psychological Reports, 52, 849-850.

Whalen, J. M., Pexman, P. M., \& Gill, A. J. (2009). “Should be fun - Not!” Incidence and marking of nonliteral language in e-mail. Journal of Language and Social Psychology, $28,263-280$.

Woodland, J. \& Voyer, D. (2011). Context and intonation in the perception of sarcasm. Metaphor and Symbol, 26, 227-239. 
Table 1. Correlations between study variables.

\begin{tabular}{|c|c|c|c|c|c|c|c|c|c|c|}
\hline & PPVT-III & BDI-II & $\begin{array}{l}\text { Belief: } \\
\text { Lit.Crit. }\end{array}$ & $\begin{array}{c}\text { Belief: } \\
\text { Lit. Comp. }\end{array}$ & $\begin{array}{l}\text { Belief: } \\
\text { Ir. Crit. }\end{array}$ & $\begin{array}{l}\text { Belief: } \\
\text { Ir. Comp. }\end{array}$ & $\begin{array}{c}\text { Intent: Lit. } \\
\text { Crit. }\end{array}$ & $\begin{array}{c}\text { Intent: } \\
\text { Lit. Comp. }\end{array}$ & $\begin{array}{l}\text { Intent: } \\
\text { Ir. Crit }\end{array}$ & $\begin{array}{c}\text { Intent: } \\
\text { Ir. Comp. }\end{array}$ \\
\hline Shyness & .10 & .25 & -.17 & -.24 & -.02 & -.14 & $-.25 \dagger$ & .08 & -.01 & $-.44 * *$ \\
\hline PPVT-III & - & -.1 & -.07 & .20 & $.33 *$ & $.29 \dagger$ & -.16 & .09 & .08 & .16 \\
\hline BDI-II & & - & .12 & -.07 & -.09 & $-.34 *$ & -.24 & $-.29 \dagger$ & -.21 & $-.26 \dagger$ \\
\hline Belief: Lit. Crit. & & & 一 & -.03 & -.03 & -.09 & .02 & -.02 & .18 & $.30 *$ \\
\hline Belief: Lit. Comp. & & & & - & -.02 & -.06 & .07 & .19 & .04 & .19 \\
\hline Belief: Ir. Crit. & & & & & - & $.29 \dagger$ & .13 & -.08 & .10 & .21 \\
\hline Belief: Ir. Comp. & & & & & & - & .13 & -.08 & -.02 & $.43 * *$ \\
\hline Intent: Lit. Crit. & & & & & & & - & $-.26 \dagger$ & $.37 *$ & .15 \\
\hline Intent: Lit. Comp. & & & & & & & & - & .01 & .08 \\
\hline Intent: Ir. Crit & & & & & & & & & - & .17 \\
\hline Intent: Ir. Comp. & & & & & & & & & & - \\
\hline Mean $(S D)$ & $\begin{array}{l}179.67 \\
(8.96)\end{array}$ & $\begin{array}{l}10.04 \\
(8.44)\end{array}$ & $\begin{array}{c}0.99 \\
(0.07)\end{array}$ & $\begin{array}{c}0.99 \\
(0.05)\end{array}$ & $\begin{array}{c}0.99 \\
(0.05)\end{array}$ & $\begin{array}{c}0.94 \\
(0.14)\end{array}$ & $\begin{array}{l}-1.68 \\
(0.74)\end{array}$ & $\begin{array}{c}2.93 \\
(0.73)\end{array}$ & $\begin{array}{l}-1.46 \\
(0.85)\end{array}$ & $\begin{array}{c}1.27 \\
(1.27)\end{array}$ \\
\hline
\end{tabular}

Lit. = literal, Ir. = Ironic, Crit. = Criticism, Comp. = Compliment, $\dagger$ indicates significance at the $90 \%$ level, $*$ indicates significance at the $95 \%$ level, $* *$ indicates significance at the $99 \%$ level 


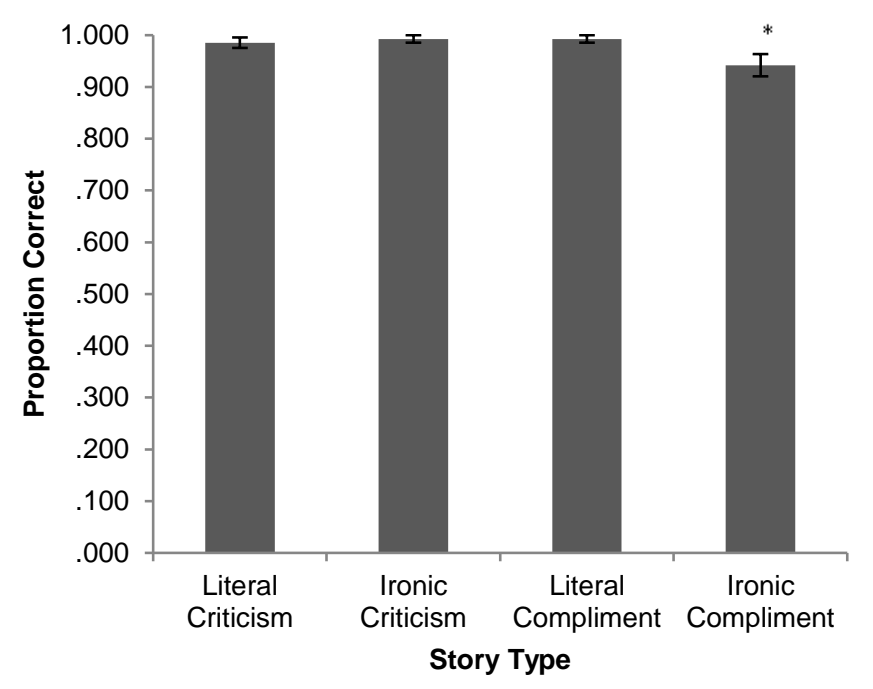

Figure 1. Participants' understanding of speaker belief as a function of story type. * Participants were marginally less accurate on ironic compliments than on literal criticisms $(p=.083)$, and significantly less accurate on ironic compliments than on ironic criticisms $(p=.033)$ and literal compliments $(p=.018)$.

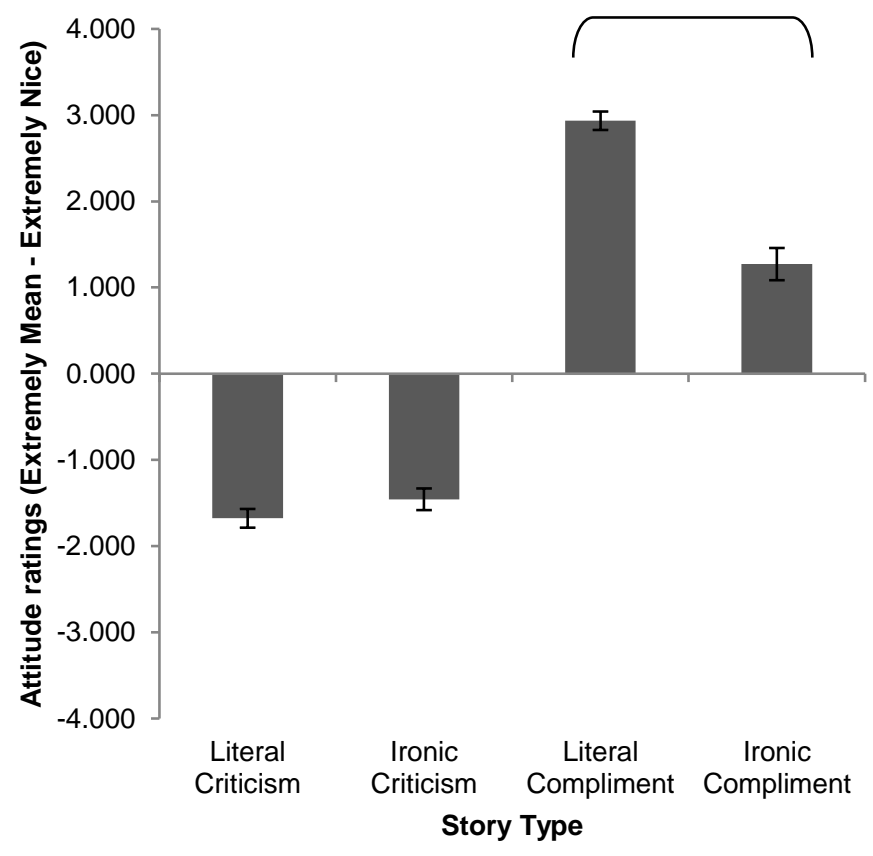

Figure 2. Participants' ratings of speakers' communicative intent varies as a function of story type. Negative ratings indicate that participants rated the speaker as "mean" while positive ratings indicate that participants rated the speaker as "nice". 


\section{Appendix A-Study Scenario and Example Comic}

Note: Different wording for the literal and ironic story types are shown in parentheses (literal/ironic)

\section{Soccer Scenario}
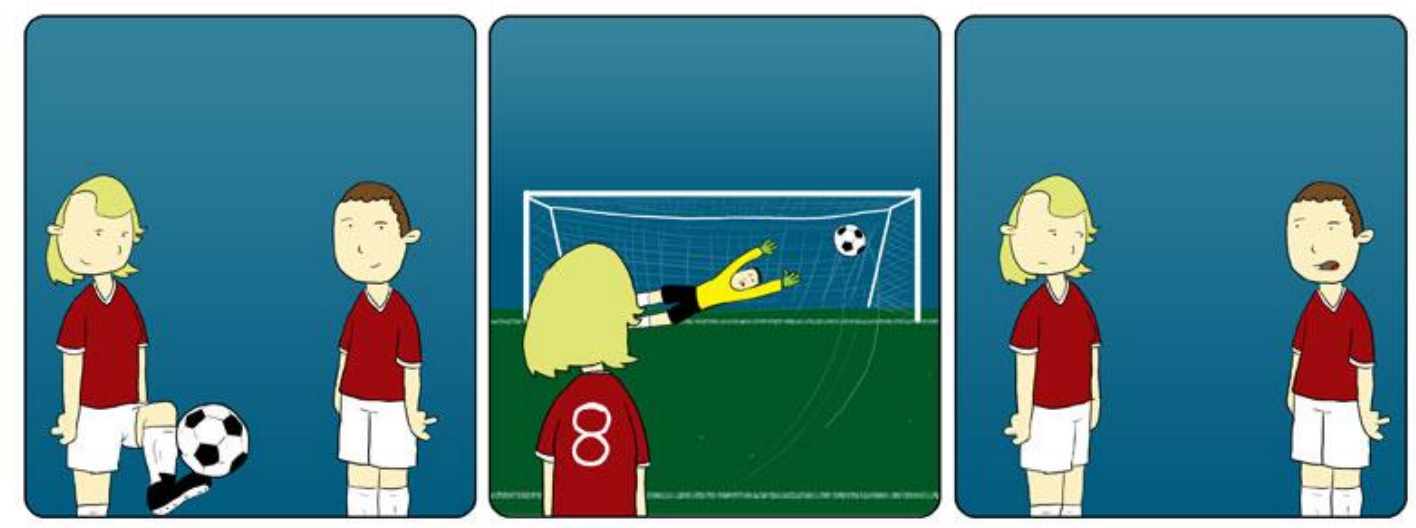

Positive Context. John plays on a soccer team with Shannon. Shannon often says she is a

(great/bad) soccer player. It is the last few minutes of a game. Shannon kicks the ball and scores

a goal. John says, "That was a really (excellent/lousy) play!”
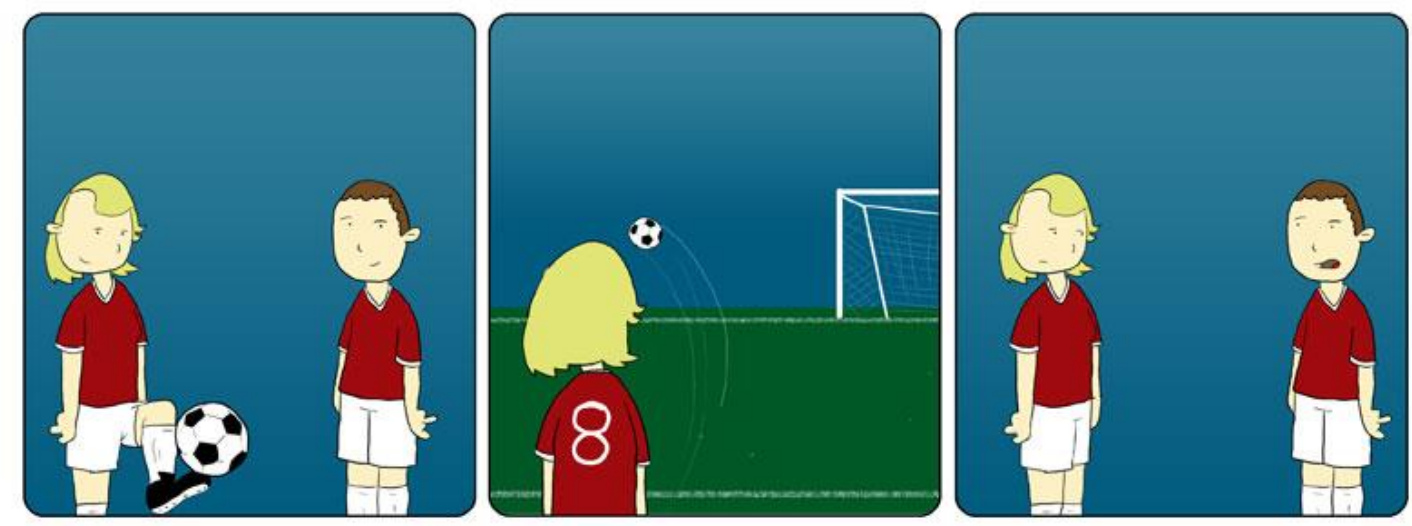

Negative Context. John plays on a soccer team with Shannon. Shannon often says she is a (bad/great) soccer player. It is the last few minutes of a game. Shannon kicks the ball and misses the net. John says, "That was a really (lousy/excellent) play!" 


\section{Appendix B - List of all Study Scenarios}

Note: Different wording for the literal and ironic story types are shown in parentheses (literal/ironic)

\section{Mini-Golf Scenario}

Positive Context. Chris and Tara are playing mini-golf on a field trip. They are on the same team. Tara thinks she is a really (good/awful) mini-golf player. Tara hits the ball and she scores a hole-in-one. Chris says, "Boy, that was an (awesome/awful) shot!"

Negative Context. Chris and Tara are playing mini-golf on a field trip. They are on the same team. Tara thinks she is a really (awful/good) mini-golf player. Tara hits the ball and completely misses the hole. Chris says, "Boy, that was an (awful/awesome) shot!"

\section{Hide and Seek Scenario}

Positive Context. Jennifer and Ryan are playing hide and seek. Ryan hides first while Jennifer counts. Ryan thinks (he has found the perfect hiding spot/his hiding spot is way too obvious). Jennifer looks everywhere for Ryan, but she doesn't find him. Jennifer says, "Wow, that was an (ideal/obvious) hiding spot!"

Negative Context. Jennifer and Ryan are playing hide and seek. Ryan hides first while Jennifer counts. Ryan thinks (his hiding spot is way too obvious/he has found the perfect hiding spot). Jennifer looks right in Ryan's spot and finds him easily. Jennifer says, "Wow, that was an (obvious/ideal) hiding spot!"

\section{Soccer Scenario}

Positive Context. John plays on a soccer team with Shannon. Shannon often says she is a (great/bad) soccer player. It is the last few minutes of a game. Shannon kicks the ball and scores a goal. John says, "That was a really (excellent/lousy) play!"

Negative Context. John plays on a soccer team with Shannon. Shannon often says she is a (bad/great) soccer player. It is the last few minutes of a game. Shannon kicks the ball and misses the net. John says, "That was a really (lousy/excellent) play!"

\section{Snowboarding Scenario}

Positive Context. Sarah and Will are snowboarding. Will tells people he can (always/never) land jumps. Will spots a jump and heads towards it. Will snowboards over the jump, spins twice in the air, and lands perfectly. Sarah says, "Wow, that was a (nice/bad) jump!"

Negative Context. Sarah and Will are snowboarding. Will tells people he can (never/always) land jumps. Will spots a jump and heads towards it. Will snowboards over the jump and lands on his face in the snow. Sarah says, "Wow, that was a (bad/nice) jump!"

\section{Video Game Scenario}


Positive Context. Ethan comes over to Fiona's house to play. They decide to play a video game. Ethan thinks he is (good/bad) at video games. Ethan's man gets to the very last level of the game. Fiona says, "You sure are (a(n) excellent/lousy) gamer."

Negative Context. Ethan comes over to Fiona's house to play. They decide to play a video game. Ethan thinks he is (bad/good) at video games. Ethan's man doesn't get past the first level of the game. Fiona says, "You sure are (a(n) lousy/excellent) gamer."

\section{Waterskiing Scenario}

Positive Context. Mark visits Lily's cottage at the lake. Mark often (brags/complains) that he is (good/bad) at waterskiing. Lily and Mark go waterskiing one day. Mark gets up easily on the skis and does five tricks. Lily says, "Wow, you are (a(n) expert/weak) skier!"

Negative Context. Mark visits Lily's cottage at the lake. Mark often (complains/brags) that he is (bad/good) at waterskiing. Lily and Mark go waterskiing one day. Mark can't get up on the skis, even after five tries. Lily says, "Wow, you are (a(n) weak/excellent) skier!"

\section{Rose Scenario}

Positive Context. Shawn and Ava attend art classes. Ava thinks she is a (good/bad) artist. The class is told to paint a picture of a rose. Ava's painting is beautiful, and looks just like a rose. Shawn says, "Woah, you are a (terrific/terrible) artist."

Negative Context. Shawn and Ava attend art classes. Ava thinks she is a (bad/good) artist. The class is told to paint a picture of a rose. Ava's painting is ugly and doesn't even resemble a rose. Shawn says, "Woah, you are a (terrible/terrific) artist."

\section{Garden Scenario}

Positive Context. Steve grows flowers in his backyard. Samantha says she is (a really good/not the best) gardener. Samantha offers to weed Steve's garden one day. Samantha finishes quickly, pulling out all the weeds, and watering the flowers. Steve says, "You are such an (awesome/awful) gardener."

Negative Context. Steve grows flowers in his backyard. Samantha says she is (not the best/a really good) gardener. Samantha offers to weed Steve's garden one day. Samantha finishes quickly, pulling out all the flowers instead of the weeds. Steve says, "You are such an (awful/awesome) gardener."

\section{Shirt Scenario}

Positive Context. Kyle and Olivia are clothes shopping. Kyle (picks out a shirt he thinks will look nice/tries a shirt, even though he thinks it will look bad) on him. Kyle changes into the shirt. (Kyle comes out to show Olivia, and/When Kyle shows Olivia) the shirt looks terrific. Olivia says, "You really picked a (fantastic/horrible) shirt!"

Negative Context. Kyle and Olivia are shopping for clothes. Kyle (tries a shirt, even though he thinks it will look bad/picks out a shirt he thinks will look nice) on him. Kyle changes into the shirt. (When Kyle 
shows Olivia/Kyle comes out to show Olivia, and), the shirt looks terrible. Olivia says, "You really picked a (horrible/fantastic) shirt!"

\section{Kite Scenario}

Positive Context. Noah and Laura go to the park with a kite that Laura made. Laura thinks her kite (will/won't) fly well. Noah asks to try Laura's kite. The kite flies easily, soaring high above them. Noah says, "You sure made (a(n) amazing/useless) kite."

Negative Context. Noah and Laura go to the park with a kite that Laura made. Laura thinks her kite (won't/will) fly well. Noah asks to try Laura's kite. The kite won't even get off the ground. Noah says, "You sure made (a(n) useless/amazing) kite."

\section{Fair Scenario}

Positive Context. Alex invites Hannah to go to the fair. Alex says there (won't/might) be line-ups. Both Hannah and Alex hate waiting in lines. Inside the fair, none of the rides have lines! Hannah says, "You sure picked the (perfect/worst) day for the fair."

Negative Context. Alex invites Hannah to go to the fair. Alex says there (might/won't) be line-ups. Both Hannah and Alex hate waiting in lines. Inside the fair, all of the rides have lines! Hannah says, "You sure picked the (worst/perfect) day for the fair."

\section{Cake Scenario}

Positive Context. Gary is at Lucy's house for dinner. For dessert, Lucy brings out a cake that she baked earlier in the day. Lucy thinks her cake (is going to be delicious/might not be very good). The cake tastes wonderful. Gary says: "Wow, you made a (delicious/horrible) cake."

Negative Context. Gary is at Lucy's house for dinner. For dessert, Lucy brings out a cake that she baked earlier in the day. Lucy thinks her cake (might not be very good/is going to be delicious). The cake tastes terrible. Gary says: "Wow, you made a (horrible/delicious) cake." 